\title{
A Casual Reading of the Corporate University
}

\section{Terrence Twomey}

Thirty years ago, Reading the Country demonstrated how connections to place could be articulated and interpreted differently. ${ }^{1}$ In particular, it gave a voice to perspectives that were largely silent in mainstream academic discussions. This essay provides a personal account of the corporate university as a place of employment for casual academics, who have become the silent and invisible majority within academic institutions. We have become a second-tier class of academics whose place within universities is increasingly precarious, ambivalent and ambiguous.

Since Reading the Country was published in 1984, universities worldwide have adopted a corporate model based on neoliberal principles. A consequence of this is the increasing casualisation of the academic workforce. In the last twenty years the number of casual or sessional academics in the Australian higher education sector has risen dramatically, with 50 to 80 per cent of the teaching load now being carried by casual employees. ${ }^{2}$ Sessional tutors are hired semester to semester on short-term contracts that are flexible in terms of duties and duration. As such, we 'are the ultimate form of contingent labour'. ${ }^{3}$ The problems associated with this practice have been qualitatively and quantitatively documented. ${ }^{4}$ In support of this research my chapter offers a personal perspective on some of the particular difficulties we experience as casual employees in a corporate place.

Lack of job security is a reality that all casual academics must deal with. As each semester comes to an end the nervous wait begins. Despite having worked as a casual in higher education for over ten years there is never a guarantee that I 
will be offered a contract for the upcoming semester. For many casuals, teaching at university is their primary, or only, source of income. This makes sessional employment particularly precarious and stressful for many academics who rely on this income. Unfortunately, the best way to ensure getting work each semester is to be complicit. Over the years I have learned that it is best not to speak out or complain about the difficulties casual staff encounter. Do not, for example, complain about the lack of appropriate space, absence of benefits afforded full time staff or having to answer hundreds of emails without remuneration, because this increases the chances your future applications will be overlooked. It also helps if you can appease the friendly benefactors that coordinate subjects and allocate work. This usually involves going above and beyond what is expected; for example, helping develop the curriculum or coordinate the tutorial program gratis will improve your chances of getting future work.

Compounding this problem are the facts that casualisation is increasing and being a casual employee makes seeking fulltime employment more difficult. Tenured and full-time employees who retire are not always replaced, which introduces more casuals into the teaching pool. More casuals and fewer permanent positions on offer mean the market for jobs in academia is highly competitive. In my experience, the main criterion being considered in job applications is the number of publications you have. You may have ten years teaching experience, but if you don't have ten peer-reviewed publications your application is not likely to make it past first base. The problem with this is that it is very difficult to produce quality research or theoretical works while working as a casual academic. During the semester, teaching and administrative duties inhibit us from doing any serious writing or research. Between semesters casuals lack the resources, funding and time that tenured staff have to produce academic research papers. In my case, despite potentially fruitful research projects that I could pursue, the motivation to write papers has waned after many years in the system without any apparent prospects for fulltime employment.

Many of my postgraduate colleagues face a related problem when trying to finish their masters or doctoral theses. 
The catch-22 here is that you cannot finish a thesis effectively while tutoring, but many postgraduates cannot afford to give up the income tutoring provides. While universities do have processes in place to avoid this situation, many postgrads delay finishing their thesis so they can maintain their income. Fortunately postgraduates have access to resources and support that can help minimise these conflicting interests. However, we itinerant workers who have completed postgraduate study don't have the same access to resources, such as the space, technologies and support services available to current students.

The flexibility and economic incentives of a predominantly casual teaching workforce are beneficial to corporate universities in several ways because they don't have to provide sessional employees with the entitlements afforded tenured and part-time staff. For example, sessional employees receive no leave loading, no penalty rates, no sick pay, no maternity or paternity leave, and they are on a reduced superannuation rate. Also, unfair dismissal laws and protections do not apply, as all sessional staff are effectively dismissed each semester. These conditions may be acceptable for employees who are only dependent on casual teaching for a short term. However, many academics like myself have been employed in a casual capacity at the same institution for more than five years. Withholding these benefits and protections from people who are effectively long-term employees is perhaps the greatest injustice sessional staff must contend with.

Casual academics also rely heavily on contacts with subject coordinators to ensure ongoing work. If the coordinator changes, casuals may lose work, as subject coordinators tend to stick to their preferred cohort of sessional tutors. There is no executive monitoring of the hiring process, as this responsibility lies with department heads and managers who tend to trust the judgment of subject coordinators. In some cases, casual academics are hired as subject coordinators, so we often rely on sessional academics themselves to administer sessional contracts. As Ryan et al. have pointed out, 'we have a professional, sophisticated knowledge based industry that is export-intensive, yet it relies on employment practices for casual academics that would be unacceptable in most other 
sectors of the economy, including the fast food industry'. ${ }^{5}$ In many respects this issue is the elephant in the room. This obvious and unacceptable situation is simply never discussed or acknowledged by the institutions that are reaping great rewards by exploiting workers in this manner.

There is an implicit expectation that casual tutors conduct unpaid duties that are directly related to their role. Departmental administrators and subject coordinators would deny this most strenuously. However, the manner in which contracts are established and implemented does not cover everything a tutor must do to teach effectively. Preparation time, reading materials, administrative obligations and attending lectures are all duties that often extend beyond what is written up in short-term contracts. In my own experience, responding to emails is a duty that we are not adequately paid for. Over the last ten years more and more time has been dedicated to answering work-related emails, a process we might call 'email creep'. In the past, if students wished to contact their tutor this had to be done during the tutorial or during the tutor's consultation hour. Today students email their tutors at any time on any day. Tutors are paid for one hour per week to be available for consultations, but this is not sufficient to cover the time spent responding to and sending emails. The ten or eleven hours per semester that tutors are paid to be available for student consultations are always used up, in particular when students need to discuss assessment and plan essays. I always spend more time in student consultations than we get paid for. The alternative would be to stop seeing students once the payment threshold has been reached, which of course would be unfair and unacceptable from a teaching perspective. The point here is that all the pay allotted for consultation is used up in consultations. However, tutors also have to answer hundreds of work-related emails during the semester. While exact figures on this are not available, it is not unreasonable to think that tutors would spend five to ten hours each semester responding to emails from students and colleagues; in my experience this is a conservative estimate.

On reading these reflections it would seem reasonable to ask, why do it? Why do unpaid work? Why work as a sessional teacher at all? As mentioned above, people do unpaid work 
and accept poor conditions because there is no other option. If you want to obtain work in the upcoming round of offers it is important that you do not complain about these conditions. However, this is not the main reason most tutors go the extra yard for students and subject coordinators. Tutors in general have a real concern for and dedication to high standards of teaching and to their students. We try to maintain a degree of professionalism and quality teaching despite the deteriorating conditions that make this more difficult each year, as class numbers increase and resources and remuneration decrease. With non-academic administrators making the decisions about how academic services will be delivered, it is unlikely that the situation for casual teachers or students in tertiary education will improve anytime in the immediate future.

Currently the situation is such that casual academics can do little to improve their lot. The tenured and full time staff that sessional staff rely on for work have little authority to advocate for them. Unfortunately, the jobs of subject coordinators are also precarious in the corporate university. Full time staff members are under pressure not to exceed departmental budgets, so paying tutors properly is not something they can push for. They have no authority over decisions like numbers of students in tutorials, how budgets are allocated, or what work tutors should be paid for.

While it does what it can, the National Tertiary Education Union (NTEU) is very limited in its capacity to improve the situation for sessional staff. For example, although the union has helped negotiate the establishment in some universities of positions that would offer casuals more job security, such as Teaching Specialist (Periodic), there is no obligation from the various schools and departments within universities to offer anyone these positions. In most respects, these are nominal not real positions. The union also relies on the solidarity of casual staff to take action against the unfair work conditions they face, but this is not a realistic option because casual academics are a disparate group. Some casuals are postgrads who probably don't see themselves as tutoring for more than a year or two, so they are not motivated to seek any long-term gains for sessional staff. Others may be financially secure retired former staff members who have no strong motivation 
to improve the conditions of all casuals. There are also 'long-term' postgraduates who are unable to complete their masters or doctorate degrees as they must take on as much sessional teaching as they can. This group is very dependent on the work and has no desire to lose opportunities through industrial action. Some may be 'outsiders' from different institutions, with no intention to rock the boat in a new work environment. Then there are 'long-term' sessional staff like me, who are keen for change to happen but don't want to make waves and so try to avoid strong action that may exclude them from future opportunities. For action to be effective all casual staff need to be unified, and this is not likely to happen. To make matters even more difficult the corporate university is very much a segmented workplace in which it has become virtually impossible for the different parts to work effectively together. We are all constrained in our capacity to take action and to teach effectively in the corporate environment.

It is very disconcerting to be a casual academic. We have highly specialised skills, yet work under conditions that would be unacceptable in any other industry. Despite this, I enjoy being a tutor. Teaching the brightest young students from around the world and helping them develop is very rewarding. I have also made some great friendships with tenured staff who support me and other tutors in my situation. I could of course just give up on academia and do something else, but I have worked towards an academic career for over ten years now and don't want to let go of that aspiration. The message I get from the corporate university is: 'if you want to be an academic, these are the conditions you must accept, and if you don't like it you can go off and do something else'. The problem with this, though, is that if others and I do give up our academic aspirations and get off the merry-go-round of sessional employment, then there simply won't be enough quality tutors to meet the demand each semester. Unfortunately, in the long run this system can only result in poorer teaching standards for the students and damaged reputations for academic institutions. There will be no winners, other than the executive staff who have implemented this system and whose only concern seems to be profits and inflating their own salaries. The corporate university is a curious place in that 


\section{it has come to value competitive marketplace strategies and incentives over their core business of providing high quality teaching services.}

\section{Notes}

$1 \quad$ Krim Benterrak, Stephen Muecke and Paddy Roe, Reading the Country: Introduction to Nomadology, Fremantle Arts Centre Press, Fremantle, 1984.

2 Suzanne Ryan, John Burgess, Julia Connell and Egbert Groen, 'Casual Academic Staff in an Australian University: Marginalised and Excluded', Tertiary Education and Management, vol. 19, no. 2, 2013, pp. 161-75.

3 Ibid., p. 162.

4 Tony Brown, James Goodman and Keiko Yasukawa, 'Academic Casualization in Australia: Class Divisions in the University', Journal of Industrial Relations, vol. 52, no. 2, 2010, pp. 169-82; Megan Kimber and Lisa C. Ehrich, 'Are Australia's Universities in Deficit? A Tale of Generic Managers, Audit Culture and Casualization', Journal of Higher Education Policy and Management, vol. 37, no. 1, 2015, pp. 83-97; Christopher J. Klopper and Bianca M. Power, 'The Casual Approach to Teacher Education: What Effect does Casulisation have for Australian University Teaching?', Australian Journal of Teacher Education, vol. 39, no. 4, 2014, pp. 101-14; Ryan, et al. 